\title{
Analysing recent Augmented and Virtual Reality developments in Tourism
}

\begin{abstract}
Purpose

Virtual Reality (VR) and Augmented Reality (AR) are two technological breakthroughs that stimulate reality perception. Both have been applied in tourism contexts to improve tourists' experience. This study aims to frame both AR and VR developments during the last 15 years from a scientific perspective.
\end{abstract}

\section{Design/methodology/approach}

This study adopts a text mining and topic modelling approach to analyse a total of 1049 articles for VR and 406 for AR. The articles were selected from Scopus, with the title, abstract, and keywords being extracted for the analysis. Formulated research hypotheses based on relevant publications are then evaluated to assess the current state of the broader scope of the large sets of literature.

\section{Findings}

Most of research using AR is based on mobile technology. Yet, wearable devices still show few publications, a gap that is expected to close in the near future. There is a lack of research adopting Big Data/machine learning approaches based on secondary data.

\section{Originality/value}

As both $\mathrm{AR}$ and VR technologies are becoming more mature, more applications to tourism emerge. Scholars need to keep pace and fill in the research gaps on both domains to move research forward.

Keywords: virtual reality; augmented reality; literature analysis; tourism. 


\section{Introduction}

Virtual Reality (VR) and Augmented Reality (AR) are two technological breakthroughs that stimulate reality perception. VR simulates real scenarios whereas AR focuses in enhancing physically-based reality perception through computer-generated sensory outputs (Gavish et al., 2015). Both appeared in the 1960s when pioneer researchers adopted 3D graphics environments. However, VR has paved a long way thanks to computer technology fast paced evolution since then, being currently adopted in a wide range of industries with effective results (Berg and Vance, 2017). On the opposite side, AR was still considered an emerging technology ten years ago and only recently has been greatly stimulated due to the major advances in mobile equipment, including smartphones, tablets and wearable devices (Van Krevelen and Poelman, 2010).

Both VR and AR have been applied in several distinct tourism contexts to improve tourists' experience. Therefore, researchers have studied both of them in tourism context during recent years (e.g., Paulo et al., 2018). The impact of VR has been analyzed by Bruno et al. (2010) in a digital archaeological exhibition context, by Huang et al. (2016) who explored VR as a tool for leveraging tourism marketing, and by Pantano and Servidio (2011) for promoting tourism destinations. Examples of AR research include improving visitors' experience through smart glasses in museums (tom Dieck et al., 2016), and marker-based AR applications in theme parks (Jung et al., 2015).

This study offers an overall scientific perspective of AR and VR evolution in tourism in the post-2000 era, enabling to understand the main trends and research gaps for both vibrant technologies. Research hypotheses grounded on existing literature are raised and validated within the broader scope of the large body of knowledge published on AR/VR in tourism. By unveiling the current state-of-the-art in the scientific literature, the contribution of this paper lies also in providing thought-provoking future directions on the application of these technologies to tourism.

\section{Literature review and research hypotheses}

According to Hobson and Williams (1995, p.128), "VR is the computer-generated medium that gives people the feeling that they are being transported from a physical 
world to a world of imagination". VR technologies provide environments where consumers can interact with simulations of real-world. These involve the use of various technologies to create environments where people can experience and interact with event simulations or build fictional scenarios. Guttentag (2010) provides an interesting review of VR uses within tourism and raises relevant questions and challenges regarding the use of VR technology to enhance and substitute tourism experiences. One may clearly perceive that VR's applications and implications for the tourism sector are vast and significant and can provide added value to this sector.

Tussyadiah et al. (2018) conducted two studies to analyse how the sense of presence during virtual walkthrough of a tourism destination influences their attitude toward a future visit. The aforementioned studies were conducted with 202 participants from Hong Kong (using VR street view of Tokyo, Japan, viewed with Google Cardboard, or VR video of Porto, Portugal, viewed with Samsung Gear VR) and 724 from the United Kingdom (using 360-degree VR videos of Lake District National Park, United Kingdom, viewed with Samsung Gear VR). They concluded that the feeling of being in the virtual environment increases enjoyment of VR experiences, the heightened feeling of being there results in stronger liking and preference for the destination, and positive attitude change leads to a higher level of visitation intention. Hyun et al. (2009) explained the typology of virtual experience in mobile context based on two dimensions: vividness and interactivity. Virtual experience is classified in different categories (from verbal-based to animated interactive experience), and based on those categories mobile applications are identified.

Instead of creating a non-real environment as in VR, AR enhances the reality by amplifying it through information technologies. Audio guides are among the first AR tools, providing interactive descriptions through numbered menus in cultural heritage sites and in museums (e.g., Bederson, 1995), with research showing evidence of the benefits of these audio devices to tourist satisfaction. The connectivity and visualization technologies have led to pocket PCs (Bellotti et al., 2002), which are upgraded versions of audio guides, with additional information available through screens, making these more appealing to tourists by a visual environment and context information using geographical information systems (Vlahakis et al., 2002).

Yet, the new millennium brought a technological breakthrough that would bring to each human's hands a device able to connect anywhere and at any time: smartphones. 
Seizing to improve tourist's experience, tourism managers incorporated these devices into their strategies by developing mobile AR applications. These applications in tourism include not only museums (Lee et al., 2015) and cultural sites (Haugstvedt and Krogstie, 2012) but also points of interest geotagged by a national tourist office (Trojan, 2016), or even a revolutionary game such as Pokémon Go which influenced users to travel while looking for the game experience (Aluri, 2017).

More recently, experiences with emerging technologies are taking place in tourism contexts. Some examples include specifically developed AR wearable technologies such as smart glasses, with tom Dieck et al. (2016) acknowledging that this is a still unchartered domain requiring additional attention in the future. Another interesting and innovative research project is the one by Rodrigues et al. (2018), where the authors propose an AR framework devoted to developing an enhanced AR system for exploring the five human senses.

As technologies keep evolving, the tourism industry tends to adopt them to improve user experience. The large quantities of online hotel reviews which result in Big Data sources are a great example (Moro et al., 2019). Likewise, both VR and AR have been experiencing advances at the rate of emergent technologies which enable new tourism applications. Currently, VR applications look more mature, with AR witnessing an exponential increase in applications thanks to mobile devices and wearable technologies. As such, we hypothesize that:

H1: VR research has been fruitful since 2000.

$\mathrm{H} 2$ : AR research has exponentially increased in the last seven years.

Table 1 summarises eight distinct studies, three of them focused on VR, and the remaining on AR. All these studies adopted a primary data-based research, consisting in interviews or responses to questionnaires, which most likely limited the number of individuals to around two hundred at most. Additionally, three of them used structural equation modelling (SEM) while two adopted linear regression to analyse the data. In a world flooded in Big Data, Table 1 suggests a scarcity of research based on secondary data. Thus, we postulate that:

H3: There is a large trend of research on AR/VR based on primary data. 
The AR studies highlighted in Table 1 are all related to the use of AR to support visitors by improving their experiences in their visits. Yet, while in the past years mobile applications have been extensively studied, the most recent years are likely to result in a new wave of research based on wearable technologies. Therefore, we hypothesize that:

H4: There is a recent exponential growth of studies based on wearable devices for AR in tourism.

H5: Mobile applications have been dominating the landscape of AR in tourism for the past 10 years (since the advent of smartphones).

Since the early 2000s, VR has been seen as a promising tool in disseminating cultural heritage throughout the world, considering this technology is available at the distance of a click (Addison, 2000). More recent studies corroborate such relevance, suggesting this trend remains up-to-date (Tussyadiah et al., 2018). Thus, we posit that:

H6: VR has been researched as a tool to help promote culture and heritage.

According to Disztinger et al. (2017), the immersion effect influences tourists' intention to use VR as a travel planning tool. Thus, VR's efficiency can promote destinations by offering an inexpensive view of the location to be visited in the near future. The placeattachment created by VR was shown to be a powerful tool in valuing the places mimicked by VR (Tussyadiah et al., 2018). Both studies suggest that:

H7: The usefulness of VR applications for tourists to plan their next visits has been one of the main trends of research in tourism.

Recently, several literature analysis studies emerged to assess the body of knowledge of technology applied to tourism. Yet, most of them address themes related to web-based services, social media or mobile services (e.g., Ukpabi and Karjaluoto, 2017; Confente, 2015). Also, with a few exceptions (e.g., Moro and Rita, 2018), most of those studies adopt a manual content analysis procedure, limiting the scope to a few tens of articles. Yung and Khoo-Lattimore (2018) analysed 46 articles and found that marketing and education were two dominant trends, although they found gaps related to awareness of the technology, usability, and time commitment. The same authors also highlighted a lack of theory-based research. Despite such lack of theory, two theoretical models were recently published for both AR (tom Dieck and Jung, 2018) and VR (Huang et al., 2016). The former is specifically focused on AR acceptance in tourism, by instantiating 
the constructs from the well-known Technology Acceptance Model (TAM) by Davis et al. (1989) to the tourism case. Relevant subjects identified by their model include "navigation", specific to AR, and "multi-language", specific to the tourism context. Both lead us to hypothesize that:

H8: Given the relevance of language and navigation capabilities to devices supporting AR in tourism, there are important topics of research focused on both.

The VR model for tourism proposed by Huang et al. (2016) is also based on TAM and it was validated in virtual tourism in Second Life. Their results suggest that perceived usefulness is associated with visually appealing elements related to the naturalistic environment and cultural authenticity. Based on their findings, we posit that:

H9: Research on VR in tourism includes trends related to cultural and environmental elements presented in VR applications.

Although the raised hypotheses are grounded on existing literature, there is lack of a holistic vision of VR/AR research in tourism, despite its importance, justifying the relevance of the present study.

\section{Methods and results}

Several databases index scientific articles and provide an easy-to-access mean of retrieving relevant literature on a given subject. In this study, Scopus was adopted, which is one of the most widely used and disseminated database worldwide (Cortez et al., 2018). Scopus indexes titles, abstracts and keywords of articles. Two distinct queries (one for VR, and the other for AR, respectively), were executed:

TITLE-ABS-KEY("virtual reality" AND (tourism OR hospitality OR tourist OR travel OR leisure)) AND SRCTYPE(j OR p OR k) AND PUBYEAR > 1999

TITLE-ABS-KEY("augmented reality" AND (tourism OR hospitality OR tourist OR travel OR leisure)) AND SRCTYPE(j OR p OR k) AND PUBYEAR > 1999

The result is a total of 1049 for VR and 406 for AR, including journal articles (parameter “j”), conference proceedings (parameter “p”), and book chapters (parameter "k") published from 2000 up to the present. Figure 1 shows the articles' distribution 
through the analysed years for both technologies. Since the articles were collected on the $1^{\text {st }}$ of June 2018, this year only accounts for articles in the January-May period, justifying the lower number found on Figure 1. It becomes clear that VR has been applied in tourism for a while (at least since 2000), with researchers acknowledging its importance. Conversely, AR's relevance to tourism has only been largely studied after 2010, with the 2010-2014 period observing a significant increase. However, while both research in AR and VR have been steadily increasing through the years, VR still seems to take most time from scholars (see 2017 and 2018 numbers).

Tables 2 and 3 show the source names that contribute the most (i.e., with more articles) for VR and AR, respectively. Specific tourism and hospitality sources appear shaded in grey. This enables to highlight that most AR and VR research has not been published in tourism sources. In fact, most of the sources are technological-related. This finding potentiates future calls by tourism outlets for further research on both technologies. Additionally, it is interesting to note that conferences are major contributors of both VR and AR (the five most relevant for both cases). Notably, the "Lecture Notes in Computer Science", a Springer series that publishes conference proceedings in several relevant information technology conferences is the first contributor, with $72 \mathrm{VR}$ articles and 38 AR articles.

The results of both queries were archived under two datasets (one for each technology), including all words used in the title, abstract, and keywords. Then, a text mining and topic modelling approach (e.g., Moro et al., 2017; Nave et al., 2018) was adopted to summarise the main results under both technologies, VR and AR. Such approach has been previously used to analyse tourism and hospitality literature from a branding and social media perspective (e.g., Moro and Rita, 2018) and to summarise the body of knowledge of Annals of Tourism Research literature (e.g., Moro et al., 2017). Nevertheless, it has not been applied to cover VR/AR literature in tourism. Also, by including articles from several sources (i.e., not restricting to tourism and hospitality literature) and by including also conference articles and book chapters, a larger body of knowledge related to the studied themes is considered, when compared to both Moro and Rita (2018) and Moro et al. (2017) studies. Additionally, such automated approach offers an objective and broader perspective on VR/AR by covering a larger number of sources when compared to traditional systematic literature reviews. 
The latent Dirichlet allocation (LDA) algorithm was chosen for gathering the topics. This algorithm provides a simple yet effective solution and has been extensively used under a large variety of contexts (e.g., Amado et al., 2018, for a literature review on Big Data in marketing; Canito et al., 2018, for news on Big Data; Calheiros et al., 2017, for sentiment analysis of an eco-hotel). The results are displayed in tables summarising the discovered topics similarly to Moro et al. (2017). For the experiments, the R statistical tool was adopted, namely both the "tm" and "topicmodels" packages, which implement the text mining and topic modelling functions.

Figures 2 and 3 exhibit the word clouds for AR and VR, respectively drawn on all the terms from the studied articles. Although each word cloud displays every single word, thus providing the full picture on the emphasis that specialized hospitality and tourism literature has been giving to each of the terms in the 2000-2018 analysed period, their corresponding word frequency tables (4 and 5) uses a skimming approach by showing the top twenty words.

The top ten topics found for AR and VR are shown in tables 6 and 7, respectively. These are presented in a descending order by the number of articles, including the four terms which best identify each topic as well as the $\beta$ distribution value (the smaller its value the stronger its relation to the topic). Articles were also grouped in three-time periods of six years $(2000-2005 ; 2006-2011 ; 2012-2018$; the latter includes also the first five months of 2018) each to facilitate the perception of evolution from a time perspective.

\section{Discussion and conclusions}

\subsection{Conclusions}

Both in AR and VR all the topics show a big jump in the last period. Yet, the incremental rate of VR research shows a steady increase for the 3 studied periods, with research even in the early 2000s showing fruitful results, with eight of the ten topics gathering more than ten publications each for the 2000-2005 period. Therefore, H1 is supported, showing a high maturity level right from 2000. The incremental increase observed may derive from a larger number of researchers pressured to publish their work (Grimes et al., 2018), as well as from incremental advances on VR technologies. 
Notwithstanding, in AR the number of articles published more recently, i.e. from 2012 onwards, account for a massive $80 \%$ of all published since 2000 , when compared to nearly $50 \%$ of VR. Thus, H2 is clearly confirmed. Further advances on wearable technologies may account in the near future for additional growth of this trend, since "wearable" was not found to be a frequent word in Table 4, paling in a green font in Figure 2, when compared to "mobile".

Both tables 6 and 7 show the lack of a combined occurrence of words such as "machine" and "learning" or "big" and "data" in a single topic. This suggests that researchers on both VR/AR are still adopting primary data-based research, which restricts data to a few hundred (see Table 1). Such result confirms H3, which points to a research gap in adopting data-driven approaches such as data mining and machine learning based on secondary data which may directly be collected from mob

ile devices or even from social media, if the goal is to assess users' opinions. This shows a clear avenue for relevant future research, which needs to keep pace with wellestablished research in tourism topics such as customer engagement and satisfaction, where researchers have already paved the way (e.g., Moro et al., 2018).

AR using wearable technology still shows little evidence of clearly emerging as a dominant trend. Topic 8 in Table 6 is the only one mentioning it, in a total of 25 articles. This corroborates tom Dieck et al. (2016)'s perceptions that this is still a topic requiring further development. Nevertheless, topic 8 also shows the exponential growth of "wearable" studies as it was hypothesized, confirming H4. Mobile is the word that occurs more often by far when considering AR research (Table 4). The unveiled topics from Table 6 give a more detailed expression to this number. Mobile is the dominant word in three out of the ten topics (second, fourth, and sixth topics), showing these are topics highly related to mobile devices/applications. Additionally, the three topics' articles are almost entirely from the two latter periods (i.e., 2006-2018), confirming H5.

The summarised body of knowledge unveiled from the topics identified in Table 7 shows VR research is in a more mature state than AR. Besides the relatively large number of articles published in the first analysed period (2000-2005), there is a significantly larger variety of words, with most topics emphasising the most relevant words as being related to the tourist experience (e.g., "heritage", "travel", "walking", "leisure", and "cultural"), when compared to AR where technological related words 
such as "mobile", "camera", “app", "data", "physical”, "wearable”, and "computing" prevail. The second topic, encompassing 138 articles, confirms H6, while the profusion of words such as "travel", "walking", "simulation", and "navigation" seems to partially grant support to H7. Yet, the lack of a single topic mentioning plan/planning clarifies that travel planning is not a main stream of research, thus rejecting H7. Most likely VR has been researched to mimic real navigation in tourism scenarios (topic \#6), but not accounting for real travel planning.

Table 6 shows that "navigation" emerges as the most relevant word in the third topic, encompassing 53 articles. Navigation appears associated with camera (needed to support navigation), location and image. Nevertheless, language does not appear in any of the topics, suggesting that the recent model proposed by tom Dieck and Jung (2018) and validated by Han et al. (2018) is still an open avenue for further research. Thus, although H8 is only supported for "navigation", the very recent above cited studies suggest that a future literature analysis is likely to uncover more research on language.

Culture is present in VR in tourism, especially associated to heritage and sites, providing evidence on VR's relevance to promote cultural dissemination. Moreover, the environment appears as the fourth most relevant word in the fifth topic, mostly associated with interaction, space and design. Additionally, nature is not appearing in any topic. Such result only partially corroborates H9 (in what is related to culture), as there is not enough evidence of a relevant trend on naturalistic environments.

\subsection{Theoretical implications}

This literature analysis framed both AR and VR current state-of-the-art literature. The undertaken approach, guided by grounded hypotheses on a subset of relevant tourism literature, helped to confirm or refute localized trends suggested by specific studies, contributing to a broader understanding of the overall body of knowledge. Although VR is in a more mature state when compared to $\mathrm{AR}$, the number of publications has been steadily increasing since 2000. Additionally, there is a consistent lack of research based on Big Data and machine learning approaches to benefit from secondary data to unearth VR/AR user experiences. Such finding uncovers an interesting avenue for future research. 


\subsection{Practical implications}

The lack of a theory-based research identified from the 46 articles analysed by Yung and Khoo-Lattimore (2018) is only partially supported by our findings based on a much larger set of literature, considering most of the hypotheses drawn from the literature were supported. Thus, the automated approach has shown to be useful by offering a broader perspective that sometimes does not agree with focused systematic quantitative literature reviews.

\subsection{Limitations and future research}

Continued research is in demand to take advantage of the most advanced text mining techniques to address issues that still pose a limitation to such approaches (e.g., word disambiguation). Nevertheless, AR and VR are still emergent technologies that require further research to assess ongoing adoption under several tourism contexts such as hotels, museums, restaurants, and tours.

\section{References}

Addison, A. C. (2000), "Emerging trends in virtual heritage", IEEE Multimedia, Vol.7 No.2,pp.22-25.

Aluri, A. (2017), "Mobile augmented reality (MAR) game as a travel guide: insights from Pokémon Go", Journal of Hospitality and Tourism Technology, Vol.8 No.1,pp.5572.

Amado, A., Cortez, P., Rita, P., and Moro, S. (2018), "Research trends on Big Data in Marketing: A text mining and topic modeling based literature analysis", European Research on Management and Business Economics, Vol.24 No.1,pp.1-7.

Bederson, B.B. (1995), "Audio augmented reality: a prototype automated tour guide", in Conference companion on Human factors in computing systems (pp.210-211). ACM.

Bellotti, F., Berta, C., De Gloria, A., and Margarone, M. (2002), "User testing a hypermedia tour guide", IEEE Pervasive Computing, Vol.1 No.2,pp.33-41. 
Berg, L. P., and Vance, J. M. (2017), "Industry use of virtual reality in product design and manufacturing: a survey", Virtual Reality, Vol.21 No.1,pp.1-17.

Bruno, F., Bruno, S., De Sensi, G., Luchi, M. L., Mancuso, S., and Muzzupappa, M. (2010), "From 3D reconstruction to virtual reality: A complete methodology for digital archaeological exhibition", Journal of Cultural Heritage, Vol.11 No.1,pp.42-49.

Calheiros, A. C., Moro, S., and Rita, P. (2017), "Sentiment classification of consumergenerated online reviews using topic modelling", Journal of Hospitality Marketing \& Management, Vol.26 No.7,pp.675-693.

Confente, I. (2015), “Twenty-five years of word-of-mouth studies: A critical review of tourism research", International Journal of Tourism Research, Vol.17 No.6,pp.613-624.

Canito, J., Ramos, P., Moro, S., and Rita, P. (2018), "Unfolding the relations between companies and technologies under the Big Data umbrella", Computers in Industry, Vol.99,pp.1-8.

Cranmer, E.E., tom Dieck, M.C., and Jung, T. (2018), "How can Tourist Attractions Profit from Augmented Reality?" in Augmented Reality and Virtual Reality (pp.21-32). Springer, Cham.

Cortez, P., Moro, S., Rita, P., King, D., and Hall, J. (2018), "Insights from a text mining survey on Expert Systems research from 2000 to 2016", Expert Systems, Vol.35 No.3,e12280.

Davis, F.D., Bagozzi, R.P., and Warshaw, P.R. (1989), "User acceptance of computer technology: a comparison of two theoretical models", Management Science, Vol.35 No.8,pp.982-1003.

Disztinger, P., Schlögl, S., and Groth, A. (2017), “Technology acceptance of virtual reality for travel planning", In Information and Communication Technologies in Tourism 2017 (pp.255-268). Springer, Cham.

Gavish, N., Gutiérrez, T., Webel, S., Rodríguez, J., Peveri, M., Bockholt, U., and Tecchia, F. (2015), "Evaluating virtual reality and augmented reality training for industrial maintenance and assembly tasks", Interactive Learning Environments, Vol.23 No.6,pp.778-798. 
Grimes, D.R., Bauch, C.T., and Ioannidis, J.P. (2018), "Modelling science trustworthiness under publish or perish pressure", Royal Society Open Science, Vol.5 No.1,171511.

Guttentag, D.A. (2010), "Virtual reality: Applications and implications for tourism.", Tourism Management, Vol.31 No.5,pp.637-651.

Han, D.I., Jung, T., and Gibson, A. (2013), "Dublin AR: implementing augmented reality in tourism", In Information and Communication Technologies in Tourism (pp.511-523). Springer, Cham.

Han, D.I., tom Dieck, M.C., and Jung, T. (2018), "User experience model for augmented reality applications in urban heritage tourism”, Journal of Heritage Tourism, Vol.13 No.1,pp.46-61.

Haugstvedt, A.C., and Krogstie, J. (2012), "Mobile augmented reality for cultural heritage: A technology acceptance study", in Mixed and Augmented Reality (ISMAR), 2012 IEEE International Symposium on (pp.247-255). IEEE.

Hobson, J.S.P., and Williams, A.P. (1995), "Virtual reality: a new horizon for the tourism industry", Journal of Vacation Marketing, Vol.1 No.2,pp.124-135.

Huang, Y.C., Backman, K.F., Backman, S.J., and Chang, L.L. (2016), "Exploring the implications of virtual reality technology in tourism marketing: An integrated research framework", International Journal of Tourism Research, Vol.18 No.2,pp.116-128.

Hyun, M.Y., Lee, S., and $\mathrm{Hu}, \mathrm{C}$. (2009), "Mobile-mediated virtual experience in tourism: concept, typology and applications", Journal of Vacation Marketing, Vol.15 No.2,pp.149-164.

Jung, T., Chung, N., and Leue, M.C. (2015), "The determinants of recommendations to use augmented reality technologies: The case of a Korean theme park", Tourism Management, Vol.49,pp.75-86.

Kourouthanassis, P., Boletsis, C., Bardaki, C., and Chasanidou, D. (2015), "Tourists responses to mobile augmented reality travel guides: The role of emotions on adoption behavior", Pervasive and Mobile Computing, Vol.18,pp.71-87.

Lee, H., Chung, N., and Jung, T. (2015), "Examining the cultural differences in acceptance of mobile augmented reality: Comparison of South Korea and Ireland", in 
Information and communication technologies in tourism 2015 (pp.477-491). Springer, Cham.

Lee, O., and Oh, J.E. (2007), “The impact of virtual reality functions of a hotel website on travel anxiety”, Cyberpsychology \& Behavior, Vol.10 No.4,pp.584-586.

Moro, S., Rita, P., and Cortez, P. (2017), "A text mining approach to analyzing Annals literature", Annals of Tourism Research, Vol.66,pp.208-210.

Moro, S., and Rita, P. (2018), "Brand strategies in social media in hospitality and tourism", International Journal of Contemporary Hospitality Management, Vol.30 No.1,pp.343-364.

Moro, S., Rita, P., and Oliveira, C. (2018), "Factors influencing hotels' online prices", Journal of Hospitality Marketing \& Management, Vol.27 No.4,pp.443-464.

Moro, S., Ramos, P., Esmerado, J., and Jalali, S.M.J. (2019), "Can we trace back hotel online reviews' characteristics using gamification features?" International Journal of Information Management, Vol.44, pp.88-95.

Nave, M., Rita, P., and Guerreiro, J. (2018), “A decision support system framework to track consumer sentiments in social media", Journal of Hospitality Marketing \& Management, Vol.27 No.6,pp.693-710.

Neuburger, L., and Egger, R. (2017), “An afternoon at the museum: through the lens of augmented reality", in Information and Communication Technologies in Tourism (pp.241-254). Springer, Cham.

Pantano, E., and Servidio, R. (2011), “An exploratory study of the role of pervasive environments for promotion of tourism destinations", Journal of Hospitality and Tourism Technology, Vol.2 No.1,pp.50-65.

Paulo, M., Rita, P., Oliveira, T., and Moro, S. (2018), "Understanding mobile augmented reality adoption in a consumer context", Journal of Hospitality and Tourism Technology. DOI: 10.1108/JHTT-01-2017-0006.

Rodrigues, J.M., Cardoso, P.J., Lessa, J., Pereira, J.A., Sardo, J.D., de Freitas, M., ... and Esteves, E. (2018), “An Initial Framework to Develop a Mobile Five Human Senses Augmented Reality System for Museums", in Handbook of Research on Technological 
Developments for Cultural Heritage and eTourism Applications (pp.96-119). IGI Global.

tom Dieck, M.C., and Jung, T. (2018), “A theoretical model of mobile augmented reality acceptance in urban heritage tourism", Current Issues in Tourism, Vol.21 No.2,pp.154-174.

tom Dieck, M.C., Jung, T., and Han, D.I. (2016), "Mapping requirements for the wearable smart glasses augmented reality museum application", Journal of Hospitality and Tourism Technology, Vol.7 No.3,pp.230-253.

Trojan, J. (2016), "Integrating AR services for the masses: geotagged POI transformation platform", Journal of Hospitality and Tourism Technology, Vol.7 No.3,pp.254-265.

Tussyadiah, I.P., Jung, T.H., and tom Dieck, M.C. (2018), “Embodiment of wearable augmented reality technology in tourism experiences", Journal of Travel Research, Vol.57 No.5, pp.597-611.

Tussyadiah, I.P., Wang, D., Jung, T.H., and tom Dieck, M.C. (2018), "Virtual reality, presence, and attitude change: Empirical evidence from tourism", Tourism Management, Vol.66,pp.140-154.

Ukpabi, D.C., and Karjaluoto, H. (2017), “Consumers' acceptance of information and communications technology in tourism: A review", Telematics and Informatics, Vol.34 No.5,pp.618-644.

Van Krevelen, D. W. F., and Poelman, R. (2010), "A survey of augmented reality technologies, applications and limitations", International Journal of Virtual Reality, Vol.9 No.2,pp.1-21.

Vlahakis, V., Ioannidis, M., Karigiannis, J., Tsotros, M., Gounaris, M., Stricker, D., ... and Almeida, L. (2002), "Archeoguide: an augmented reality guide for archaeological sites", IEEE Computer Graphics and Applications, Vol.22 No.5,pp.52-60.

Yung, R., and Khoo-Lattimore, C. (2018), "New realities: a systematic literature review on virtual reality and augmented reality in tourism research", Current Issues in Tourism, DOI: $10.1080 / 13683500.2017 .1417359$. 


\section{Figures}

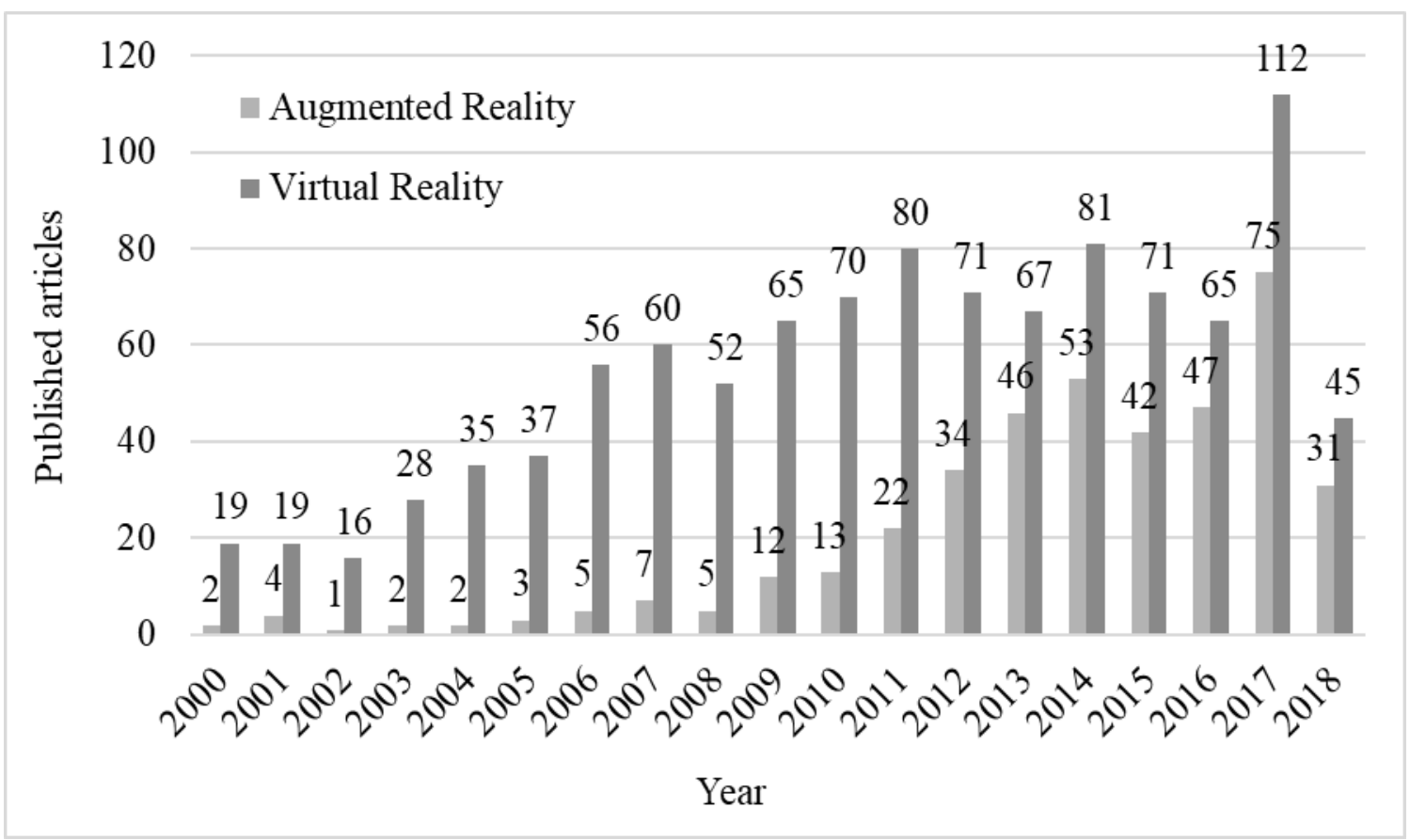

Figure 1 - Distribution of articles throughout the studied years. 


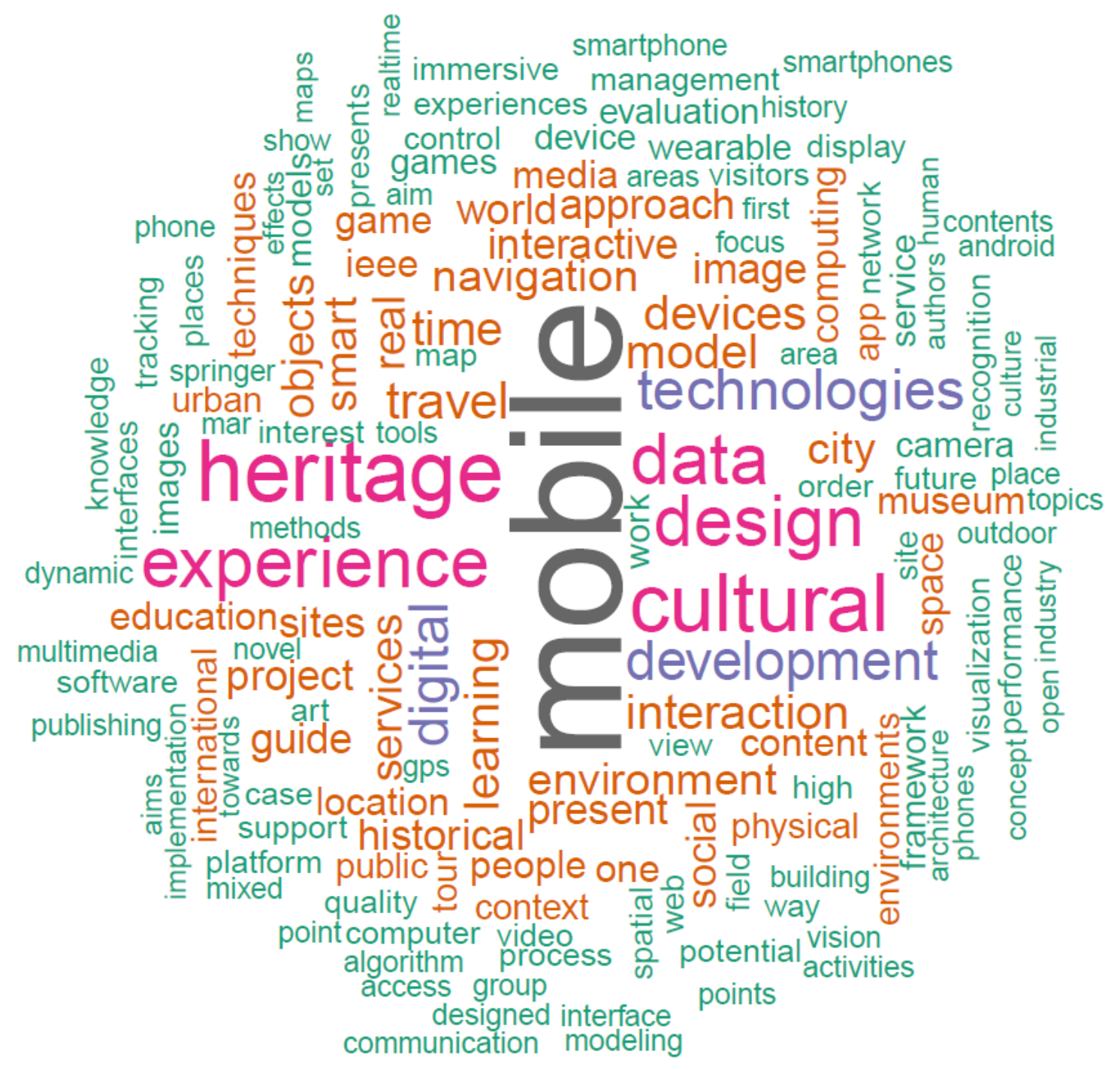

Figure 2 - Word cloud for AR. 


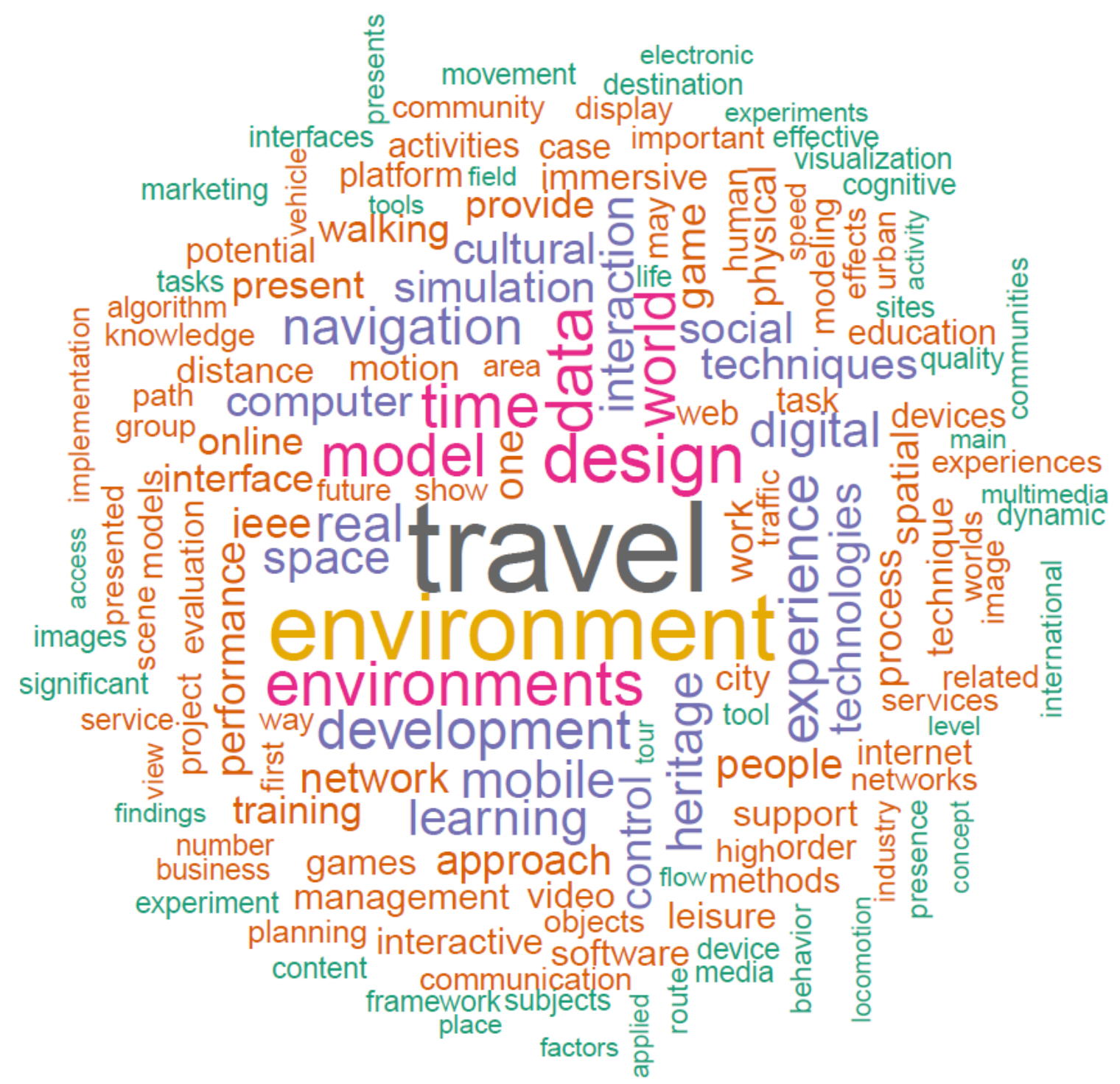

Figure 3 - Word cloud for VR. 
Table 1 - VR/AR studies applied to tourism.

\begin{tabular}{|c|c|c|c|c|c|}
\hline & Reference & Context & Data & Method of analysis & Major findings \\
\hline \multirow{3}{*}{ VR } & $\begin{array}{l}\text { (Pantano and } \\
\text { Corvello, 2014) }\end{array}$ & $\begin{array}{l}\text { Virtual tour for } \\
\text { an } \\
\text { archaeological } \\
\text { site in Italy }\end{array}$ & $\begin{array}{l}100 \\
\text { interviews }\end{array}$ & $\begin{array}{l}\text { Technology- } \\
\text { Acceptance Model; } \\
\text { SEM }\end{array}$ & $\begin{array}{l}\text { Both perceived usefulness and } \\
\text { enjoyment have an impact on } \\
\text { behavioral intention }\end{array}$ \\
\hline & $\begin{array}{l}\text { (Lee and Oh, } \\
\text { 2007) }\end{array}$ & $\begin{array}{l}\text { VR features in } \\
\text { a hotel website }\end{array}$ & $\begin{array}{l}51 \\
\text { responses }\end{array}$ & Linear regression & $\begin{array}{l}\text { There is a relation between travel } \\
\text { anxiety and psychological relief } \\
\text { caused by using VR }\end{array}$ \\
\hline & $\begin{array}{l}\text { (Disztinger et al., } \\
\text { 2017) }\end{array}$ & $\begin{array}{l}\text { VR for Travel } \\
\text { Planning }\end{array}$ & $\begin{array}{l}148 \\
\text { responses }\end{array}$ & Linear regression & $\begin{array}{l}\text { Immersion, interest, enjoyment } \\
\text { and usefulness impact intention to } \\
\text { use VR }\end{array}$ \\
\hline \multirow{3}{*}{$\mathbf{A R}$} & $\begin{array}{l}\text { (Kourouthanassis } \\
\text { et al., 2015) }\end{array}$ & $\begin{array}{l}\text { Mobile travel } \\
\text { guide for } \\
\text { Corfu, Greece }\end{array}$ & $\begin{array}{l}105 \\
\text { responses }\end{array}$ & $\begin{array}{l}\text { PAD emotional state } \\
\text { model; Partial least } \\
\text { squares (PLS) SEM }\end{array}$ & $\begin{array}{l}\text { The AR implemented application } \\
\text { evokes feelings of pleasure, which } \\
\text { influence behavioral intention }\end{array}$ \\
\hline & $\begin{array}{l}\text { (Han et al., } \\
\text { 2013) }\end{array}$ & $\begin{array}{l}\text { Mobile } \\
\text { application for } \\
\text { urban heritage } \\
\text { in Dublin }\end{array}$ & $\begin{array}{l}26 \\
\text { interviews }\end{array}$ & $\begin{array}{l}\text { Thematic analysis } \\
\text { technique to analyze } \\
\text { the transcripts }\end{array}$ & $\begin{array}{l}\text { AR is being implemented in a } \\
\text { meaningful way in the tourism } \\
\text { industry }\end{array}$ \\
\hline & $\begin{array}{l}\text { (Tussyadiah } e t \\
\text { al., 2018) }\end{array}$ & $\begin{array}{l}\text { Wearable } \\
\text { devices for AR } \\
\text { in an art gallery } \\
\text { in UK }\end{array}$ & $\begin{array}{l}211 \\
\text { responses }\end{array}$ & $\begin{array}{l}\text { Co-variance-based } \\
\text { SEM }\end{array}$ & $\begin{array}{l}\text { AR embodiment encompasses } \\
\text { ownership, location, and } \\
\text { agency }\end{array}$ \\
\hline
\end{tabular}




\begin{tabular}{|c|c|c|c|c|}
\hline $\begin{array}{l}\text { (Cranmer et al., } \\
\text { 2018) }\end{array}$ & $\begin{array}{l}\text { Revenue model } \\
\text { for AR } \\
\text { implementation } \\
\text { in a Museum, } \\
\text { in UK }\end{array}$ & $\begin{array}{l}50 \text { semi- } \\
\text { structured } \\
\text { interviews } \\
\text { of museum } \\
\text { stakeholders }\end{array}$ & $\begin{array}{l}\text { Content analysis of } \\
\text { interviews }\end{array}$ & $\begin{array}{l}\text { AR implementation can contribute } \\
\text { to increased profits }\end{array}$ \\
\hline $\begin{array}{l}\text { (Neuburger and } \\
\text { Egger, 2017) }\end{array}$ & $\begin{array}{l}\text { Museum } \\
\text { experience in } \\
\text { Salzburg, } \\
\text { Austria }\end{array}$ & $\begin{array}{l}176 \\
\text { responses }\end{array}$ & Independent t-test & $\begin{array}{l}\text { AR can be used in the curation } \\
\text { process, by facilitating and } \\
\text { enhancing the presentation of } \\
\text { exhibits in a museum }\end{array}$ \\
\hline
\end{tabular}


Table 2 - Sources for VR articles.

\begin{tabular}{|lr|}
\hline VR Sources & $\begin{array}{r}\text { Nr. } \\
\text { Articles }\end{array}$ \\
\hline Lecture Notes in Computer Science & 72 \\
Proceedings - IEEE Virtual Reality & 23 \\
ACM International Conference Proceeding Series & 19 \\
Proceedings of SPIE - The International Society for Optical & 18 \\
Engineering & 13 \\
Proceedings of the ACM Symposium on Virtual Reality Software and & \\
Technology, VRST & 11 \\
Conference on Human Factors in Computing Systems - Proceedings & 11 \\
IEEE Transactions on Visualization and Computer Graphics & 9 \\
Cyberpsychology and Behavior & 8 \\
International Archives of the Photogrammetry, Remote Sensing and & \\
Spatial Information Sciences - ISPRS Archives & 8 \\
PLoS ONE & 8 \\
Applied Mechanics and Materials & 7 \\
Advanced Materials Research & 7 \\
Virtual Reality & 6 \\
Tourism Management & 6 \\
Communications in Computer and Information Science & 6 \\
Computers in Human Behavior & 6 \\
Xitong Fangzhen Xuebao / Journal of System Simulation & 6 \\
ACM Transactions on Applied Perception &
\end{tabular}


Table 3 - Sources for AR articles.

\begin{tabular}{|lr|}
\hline AR Sources & $\begin{array}{r}\text { Nr. } \\
\text { Articles }\end{array}$ \\
\hline Lecture Notes in Computer Science & 38 \\
ACM International Conference Proceeding Series & 13 \\
International Archives of the Photogrammetry, Remote Sensing and & 8 \\
Spatial Information Sciences - ISPRS Archives & \\
Procedia Computer Science & 8 \\
Lecture Notes in Electrical Engineering & 6 \\
Conference on Human Factors in Computing Systems - Proceedings & 5 \\
Journal of Telecommunication, Electronic and Computer Engineering & 5 \\
Current Issues in Tourism & 4 \\
AIP Conference Proceedings & 4 \\
Lecture Notes in Geoinformation and Cartography & 4 \\
Journal of Heritage Tourism & 3 \\
Multimedia Tools and Applications & 3 \\
Advances in Intelligent Systems and Computing & 3 \\
Proceedings of the ACM Symposium on Virtual Reality Software and & 3 \\
Technology, VRST & \\
Communications in Computer and Information Science & 3 \\
Journal of Hospitality and Tourism Technology & 3 \\
Applied Mechanics and Materials & 3 \\
Advanced Materials Research & 3 \\
CEUR Workshop Proceedings & 3 \\
Proceedings of SPIE - The International Society for Optical Engineering & 3 \\
\hline
\end{tabular}


Table 4 - Word frequency for AR.

\begin{tabular}{|lr|}
\hline Word & Frequency \\
\hline mobile & 581 \\
heritage & 283 \\
cultural & 269 \\
experience & 228 \\
design & 227 \\
data & 218 \\
technologies & 165 \\
digital & 154 \\
development & 149 \\
travel & 134 \\
model & 130 \\
time & 129 \\
interaction & 129 \\
learning & 123 \\
devices & 119 \\
navigation & 115 \\
real & 115 \\
environment & 113 \\
services & 109 \\
smart & 106 \\
\hline
\end{tabular}


Table 5 - Word frequency for VR.

\begin{tabular}{|lr|}
\hline Word & Frequency \\
\hline travel & 966 \\
environment & 664 \\
design & 459 \\
data & 445 \\
time & 413 \\
model & 395 \\
world & 365 \\
experience & 343 \\
development & 341 \\
navigation & 326 \\
mobile & 323 \\
real & 322 \\
heritage & 295 \\
digital & 292 \\
learning & 288 \\
interaction & 270 \\
space & 267 \\
simulation & 263 \\
techniques & 261 \\
social & 261 \\
\hline
\end{tabular}


Table 6 - Topics for AR.

\begin{tabular}{|c|c|c|c|c|c|c|c|c|c|c|c|c|}
\hline \multirow{2}{*}{ \# } & \multirow{2}{*}{$\begin{array}{c}\mathrm{Nr} . \\
\text { Articles }\end{array}$} & \multicolumn{2}{|c|}{ word 1} & \multicolumn{2}{|c|}{ word 2} & \multicolumn{2}{|c|}{ word 3} & \multicolumn{2}{|l|}{ word 4} & \multirow{2}{*}{$2000-2005$} & \multirow{2}{*}{ 2006-2011 } & \multirow{2}{*}{ 2012-2018 } \\
\hline & & & $\beta$ & & $\beta$ & & $\beta$ & & $\beta$ & & & \\
\hline 1 & 65 & heritage & 2.50 & cultural & 2.68 & sites & 3.66 & learning & 3.76 & 1 & 7 & 57 \\
\hline 2 & 56 & mobile & 2.41 & smart & 3.86 & city & 3.89 & game & 3.92 & 1 & 12 & 43 \\
\hline 3 & 53 & navigation & 3.32 & camera & 3.63 & location & 3.97 & image & 4.00 & 5 & 11 & 37 \\
\hline 4 & 49 & mobile & 2.96 & objects & 3.55 & services & 3.68 & devices & 4.23 & 3 & 13 & 33 \\
\hline 5 & 44 & interaction & 3.37 & space & 3.64 & design & 3.83 & environment & 4.02 & 0 & 8 & 36 \\
\hline 6 & 43 & mobile & 3.30 & app & 3.59 & experience & 3.98 & design & 3.99 & 1 & 3 & 39 \\
\hline 7 & 37 & social & 3.51 & physical & 3.80 & people & 4.02 & model & 4.02 & 0 & 4 & 33 \\
\hline 8 & 25 & experience & 2.69 & wearable & 3.19 & computing & 3.60 & context & 3.93 & 1 & 4 & 20 \\
\hline 9 & 22 & design & 3.60 & algorithm & 3.83 & control & 4.08 & data & 4.16 & 0 & 2 & 20 \\
\hline 10 & 12 & data & 2.63 & model & 3.88 & web & 3.90 & spatial & 4.07 & 2 & 0 & 10 \\
\hline
\end{tabular}


Table 7 - Topics for VR.

\begin{tabular}{|c|c|c|c|c|c|c|c|c|c|c|c|c|}
\hline \multirow{2}{*}{ \# } & \multirow{2}{*}{$\begin{array}{c}\mathrm{Nr} . \\
\text { Articles }\end{array}$} & \multicolumn{2}{|l|}{ word 1} & \multicolumn{2}{|c|}{ word 2} & \multicolumn{2}{|l|}{ word 3} & \multicolumn{2}{|l|}{ word 4} & \multirow{2}{*}{$2000-2005$} & \multirow{2}{*}{ 2006-2011 } & \multirow{2}{*}{ 2012-2018 } \\
\hline & & & $\beta$ & & $\beta$ & & $\beta$ & & $\beta$ & & & \\
\hline 1 & 156 & game & 3.62 & social & 3.79 & online & 3.89 & community & 4.05 & 7 & 59 & 90 \\
\hline 2 & 132 & heritage & 3.18 & cultural & 3.36 & project & 4.18 & development & 4.29 & 14 & 47 & 71 \\
\hline 3 & 132 & travel & 3.04 & navigation & 3.29 & environment & 3.39 & techniques & 3.62 & 23 & 42 & 67 \\
\hline 4 & 128 & mobile & 3.17 & environment & 3.97 & visualization & 4.28 & scene & 4.41 & 17 & 67 & 44 \\
\hline 5 & 108 & design & 3.07 & space & 3.85 & digital & 4.11 & interaction & 4.13 & 13 & 41 & 54 \\
\hline 6 & 98 & travel & 2.97 & simulation & 3.85 & traffic & 3.90 & vehicle & 3.91 & 21 & 31 & 46 \\
\hline 7 & 98 & performance & 3.66 & walking & 3.72 & distance & 3.78 & travel & 3.83 & 15 & 39 & 44 \\
\hline 8 & 88 & leisure & 4.09 & health & 4.13 & patients & 4.22 & experience & 4.33 & 20 & 16 & 52 \\
\hline 9 & 79 & data & 3.33 & city & 3.65 & urban & 3.94 & model & 3.98 & 18 & 30 & 31 \\
\hline 10 & 30 & learning & 3.12 & software & 3.89 & network & 3.94 & computer & 4.02 & 6 & 11 & 13 \\
\hline
\end{tabular}

